\title{
Solitary rectal ulcer syndrome presenting with rectal prolapse, severe mucorrhea and eroded polypoid hyperplasia: Case report and review of the literature
}

\author{
Deepak V Gopal MD FRCPC ${ }^{1}$, Christopher Young MD², Ronald M Katon MD ${ }^{1}$
}

DV Gopal, C Young, RM Katon. Solitary rectal ulcer syndrome presenting with rectal prolapse, severe mucorrhea and eroded polypoid hyperplasia: Case report and review of the literature. Can J Gastroenterol 2001;15(7):479-483. A case of solitary rectal ulcer syndrome in a 36-year-old woman presenting with severe, persistent mucorrhea and eroded polypoid hyperplasia as the predominant clinical features, who was ultimately noted to have symptoms of rectal prolapse, is presented. Endoscopically, she had multiple (50 to 60 ) small, whitish polypoid lesions in the rectum that were initially misinterpreted as being a carpeted villous adenoma, juvenile polyposis or atypical proctitis. The lesions were treated with argon plasma coagulation with resolution, but a solitary rectal ulcer developed. The patient then admitted to a history of massive rectal prolapse over the preceding six months and underwent surgical treatment. Severe mucorrhea as the presenting feature and the presence of multiple polypoid lesions consistent with a histological diagnosis of eroded polypoid hyperplasia make the present case unique.

Key Words: Mucorrhea; Polypoid hyperplasia; Solitary rectal ulcer syndrome

\section{Syndrome de l'ulcère solitaire du rectum accompagnant un prolapsus rectal, une mucorrhée grave et une hyperplasie polypoïde érodée : exposé de cas et examen de la documentation}

\begin{abstract}
Voici le cas d'une femme de 36 ans souffrant du syndrome de l'ulcère solitaire du rectum, dont les principales manifestations cliniques se composaient de mucorrhée persistante grave et d'une hyperplasie polypoïde érodée; on a finalement noté des symptômes de prolapsus rectal. L'endoscopie a révélé la présence de multiples (50 à 60) petites lésions polypoïdes blanchâtres dans l'ampoule rectale; ces lésions avaient été faussement diagnostiquées comme un tapis d'adénomes villeux, une polypose juvénile ou une rectite atypique. Le traitement des lésions à l'aide de la coagulation au plasma-argon a porté fruit mais a été suivi de l'apparition d'un ulcère solitaire du rectum. La patiente a alors avoué qu'elle avait eu des antécédents de prolapsus rectal massif au cours des six mois précédents et qu'elle avait subi une intervention chirurgicale. La présence de mucorrhée grave comme premier signe de la maladie et de lésions polypoïdes multiples compatibles avec un diagnostic histologique d'hyperplasie polypoïde érodée donne au cas son caractère singulier.
\end{abstract}

Qolitary rectal ulcer syndrome (SRUS) is a benign condi$\checkmark$ tion affecting the rectum that generally pursues a chronic course of rectal bleeding, mucorrhea and tenesmus (1). Severe mucorrhea as the major presenting symptom is uncommon and can lead to misdiagnosis. Endoscopically, only $35 \%$ of these rectal lesions are solitary ulcers, $22 \%$ are multiple ulcers and $44 \%$ show polypoid lesions with patchy, granular and hyperemic mucosa (2). A case of solitary rectal ulcer syndrome in a woman who presented with extreme mucorrhea and minimal rectal bleeding is presented. The

\footnotetext{
${ }^{1}$ Division of Gastroenterology and ${ }^{2}$ Department of Pathology, Oregon Health Sciences University, Portland, Oregon, USA

Correspondence: Dr Ronald M Katon, PV-310, Division of Gastroenterology, Oregon Health Sciences University, 3181 SW Sam Jackson Park Road, Portland, Oregon 97201-3098, USA. Telephone 503-494-6398, fax 503-494-7556, e-mail katonr@ohsu.edu

Received for publication January 24, 2000. Accepted September 6, 2000
} 


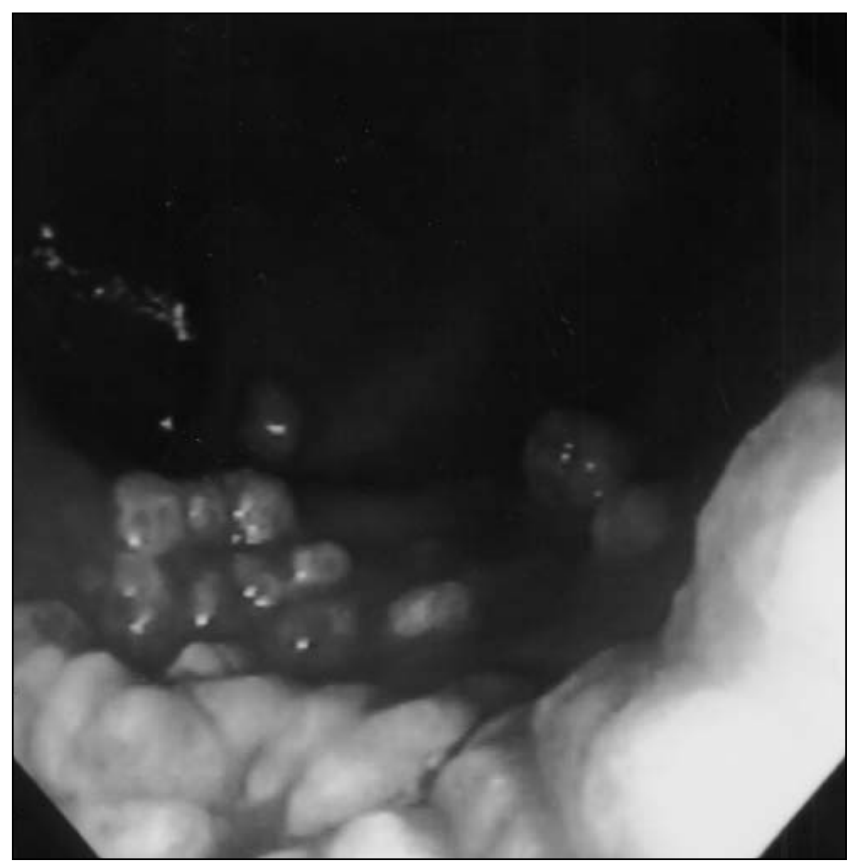

Figure 1) Flexible sigmoidoscopy revealing multiple rectal polypoid lesions at 5 to $15 \mathrm{~cm}$ above the anal verge
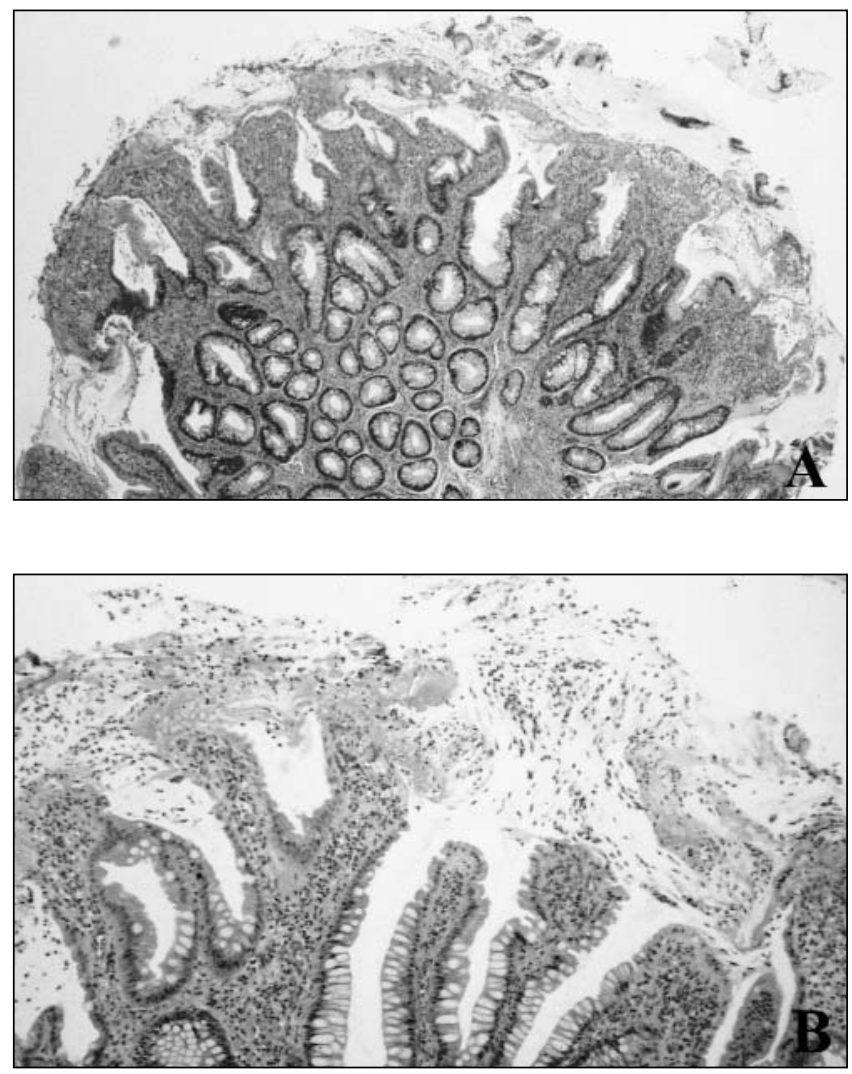

Figure 2) A Histopathology of a polypoid lesion with surface erosion, reactive glands and fibrinomucinous exudate (hemotoxylin and eosin stain, original magnification $\times 40$ ). B Close up of polypoid surface showing epithelial erosions and fibrinomucinous exudate (hemotoxylin and eosin stain, original magnification $\times 100$ )

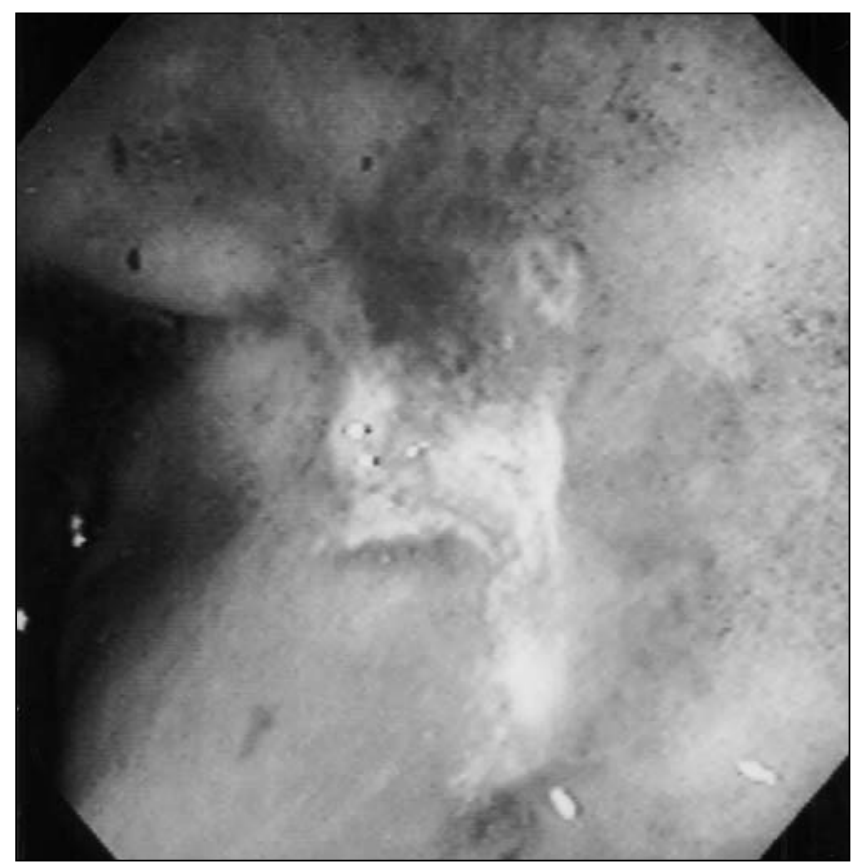

Figure 3) Endoscopic findings of a solitary rectal ulcer after two treatments with argon plasma coagulation

initial sigmoidoscopic appearance was compatible with eroded polypoid hyperplasia, which later progressed to solitary rectal ulcer. Misinterpretation of the significance of the nodular lesions led to the preliminary diagnoses of villous adenoma, atypical proctitis and juvenile polyposis, which caused a delay in the final diagnosis and appropriate therapy.

\section{CASE PRESENTATION}

A 36-year-old woman was referred to the authors' institution for endoscopic evaluation and management of abnormal findings noted on colonoscopy. She had developed symptoms of severe, persistent mucorrhea, left lower quadrant and perianal pain, and minimal rectal bleeding over a three-month period. The mucorrhea occurred day and night, necessitating the wearing of diapers, and forced the patient to quit her employment. Past medical history was negative for inflammatory bowel disease or colorectal malignancy. Physical examination was essentially unremarkable. Rectal examination revealed mucous discharge with minimal blood but no other significant findings. Initially, no obvious rectal prolapse was observed.

Initial colonoscopy at the referring hospital revealed numerous polypoid lesions in the rectum. The gross appearance suggested a carpeted villous adenoma, but biopsies disclosed nonspecific inflammation. Rectal installation of 5-aminosalicylate (5-ASA) (Rowasa; Solvay Pharmaceuticals Inc, USA) enemas failed to alleviate symptoms and the patient was referred to the authors' institution for atypical proctitis. Repeat flexible sigmoidoscopy done at the authors' institution showed 50 to 60 small, whitish polypoid lesions 5 to $15 \mathrm{~cm}$ from the anal verge in 
the rectum only (Figure 1). Biopsies taken of six representative polyps showed inflammation of the lamina propria with associated surface erosions consistent with inflammatory, juvenile-type polyps versus hamartomatous polyps (Figures 2A,2B). On two follow-up occasions, these suspected juvenile polyps were treated with argon plasma coagulation (APC) (ERBE APC 300; ERBE USA Inc, USA) treatment (3); however, the mucorrhea persisted. On her third followup flexible sigmoidoscopy, the nodular lesions were no longer present, but she had a $1 \times 1.5 \mathrm{~cm}$ solitary rectal ulcer (Figure 3). At that point, the patient was asked specifically about rectal prolapse and admitted that she indeed had noted progressive and massive rectal prolapse following defecation over the prior six months.

She subsequently underwent surgery for her symptomatic rectal prolapse with a Ripstein procedure, where a sacral sling was performed using a marlex mesh and sewn to the anterior and side wall of the rectum (4). Her symptoms of mucorrhea subsided shortly after surgery. Follow-up flexible sigmoidoscopy performed six months later showed intact rectal mucosa without findings of ulceration or polypoid lesions.

\section{DISCUSSION}

SRUS is a benign condition affecting the rectum, which usually presents in women during the third and fourth decades of life, pursuing a chronic course of constipation, mucorrhea, associated rectal prolapse, rectal bleeding and tenesmus $(1,2,5)$. The etiology of this syndrome is thought to be associated with either overt rectal prolapse or internal intussusception, where excessive straining during defecation forces the anterior rectal mucosa downwards against the unyielding pelvic floor, causing trauma and focal ischemia to the mucosa (1-7). Mucosal prolapse with either full thickness rectal prolapse or occult rectal intussusception causes excessive movement of mucosa, and the ischemia that results is due to a combination of traction forces on submucosal vessels, obliteration of submucosal capillaries by fibromuscular proliferation and resulting pressure necrosis of prolapsed mucosa by the anal sphincters (6-9).

The clinical presentation can be variable, as Tjandra et al (1) noted in an earlier retrospective review of 80 patients with SRUS. In their group, the average age at diagnosis was 48.7 years, with a slight female to male predilection with a ratio of 1.4 to 1.0. Seventy-four per cent of patients had nonspecific bowel disturbances consisting of constipation or diarrhea, $56 \%$ had rectal bleeding and $26 \%$ were asymptomatic. Approximately $25 \%$ of patients' conditions were misdiagnosed (Table 1) at the time of initial assessment, proving that this syndrome can be easily missed if specific details in history, course and physical examination are not noted $(1,10)$. Rectal prolapse was associated in $28 \%$ of cases.

Mucorrhea occurs in SRUS but is not often the predominant symptom, usually it is overshadowed by tenesmus, constipation, diarrhea, abdominal pain and rectal bleeding. The pathophysiology of mucorrhea in SRUS is unclear, but may be due to altered mucin production by direct stimuli
TABLE 1

Differential diagnosis of solitary rectal ulcer syndrome

\begin{tabular}{lc}
\hline Clinical/endoscopic presentation & References \\
\hline Colitis cystica profunda & 7 \\
Idiopathic inflammatory bowel disease & 13,22 \\
Rectal neoplasms & \\
$\quad$ Adenocarcinoma & 23 \\
$\quad$ Benign adenomatous polyps & 24 \\
Infectious colitis & 12 \\
$\quad$ Human immunodeficiency virus- & 25 \\
$\quad$ associated rectal ulcers & \\
Drugs & 26 \\
$\quad$ Oral contraceptives & 27 \\
Nonsteroidal anti-inflammatory drugs & 28 \\
Ergotamine & 29 \\
Colonoscopy bowel preparations & 30 \\
Stercoral ulcer & 13,14 \\
Pseudomembranous colitis & 22 \\
Ischemic colitis & 31 \\
Radiation colitis & 32 \\
Submucosal lipoma &
\end{tabular}

due to ischemia and trauma affecting glycoprotein synthesis and indirectly via cell proliferation $(11,12)$. All mucosal biopsy specimens of the solitary rectal ulcer show the characteristic findings of fibrous obliteration of the lamina propria, disorganization of the muscularis mucosa with extension of muscle fibres into the lamina propria and regenerative crypt epithelium changes with villous configuration and distorted mucosal gland architecture (8-11).

There is an interesting association of polypoid features associated with rectal prolapse, and some authors suggest that this may be a variant of SRUS $(13,14)$. The common features are numerous polyps in the rectosigmoid; signs and symptoms consistent with inflammatory bowel disease, including hematochezia, mucorrhea and tenesmus; negative family history of polyposis or evidence of infection; and histopathology showing minimally inflamed polypoid hyperplastic mucosa with surface erosions and pseudomembranes. This variant of SRUS was described as eroded polypoid hyperplasia, which may be similar to the endoscopic features seen in our case $(13,14)$.

In our case, the multiple polypoid lesions in the rectum were ablated by APC, but severe mucorrhea persisted. It was only during her third follow-up flexible sigmoidoscopy evaluation that we elucidated the history of rectal prolapse, which was then observed on straining. The occurrence of solitary rectal ulcer may represent the evolution from polypoid to ulcerative change in our patient with severe rectal prolapse. However, it is conceivable that APC may have led to a further weakening in the muscularis layer, predisposing the patient to further rectal prolapse and a solitary rectal ulcer (3). 
When clinical symptoms have been elucidated and flexible sigmoidoscopy has been performed, other investigations are rarely required and have a limited value in confirming SRUS or rectal prolapse (15). Occasionally a barium enema may show nodularity of the rectal mucosa and thickening of the first valve of Houston, but ulceration is not often shown and in $40 \%$ to $50 \%$ of cases the study is normal $(15,16)$. Video defecography can be performed if occult prolapse is suspected and may show failure of relaxation of the puborectalis muscle, changes in the anorectal angle and mucosal abnormalities with internal prolapse $(15,17)$. Physiological studies such as anorectal manometry are unlikely to yield significant information on etiology, but reports have demonstrated that concentric needle electromyographic studies of the puborectalis often show failure of relaxation during defecation in $50 \%$ of cases with SRUS and may indicate damage to innervation of that muscle $(15,18)$. Overall, previous studies have shown inconsistent findings, and the results of anorectal manometry do not contribute to making the diagnosis or to predicting therapeutic response $(15,18)$. Rectal endoscopic ultrasound may reveal thickening of the muscularis propria and, in some cases, thickening of the internal anal sphincter. The latter is most likely due to abnormal defecation, repeated trauma and ischemia, but this is not a universal finding and associated primary abnormalities must be excluded $(15,19)$. In our case, because the patient was still symptomatic with persistent mucorrhea when the clinical diagnosis of rectal prolapse was made, given the limitations of these other tests, a decision was made to proceed directly to surgery.

The management of this condition is based on the presence of symptoms (15). Usually nonoperative treatment is attempted with bulk laxatives and bowel retraining before considering surgical options for intractable or worsening symptoms. Conservative medical management can include local treatment with application of local steroids, 5-ASA products or sucralfate enemas, but these products have usually been unsuccessful in treating the underlying defecatory disorder, although macroscopic healing did occur (15). Dietary treatment with fibre and bulk-forming agents is often recommended, but there is little evidence to support this and the literature has reported various response rates

\section{REFERENCES}

1. Tjandra JJ, Fazio VW, Church JM, Lavery IC, Oakley JR, Milsom JW. Clinical conundrum of solitary rectal ulcer. Dis Colon Rectum 1992;35:227-34.

2. Ho YH, Ho JMS, Parry BR, Goh HS. Solitary rectal ulcer syndrome: The clinical entity and anorectal physiological findings in Singapore. Aust NZ J Surg 1995;65:93-7.

3. Johanns W, Luis W, Janssen J, Kahl S, Greiner L. Argon plasma coagulation (APC) in gastroenterology experimental and clinical experiences. Eur J Gastroenterol Hepatol 1997;9:581-7.

4. Knoepp LF, Davis WM. Solitary rectal ulcer syndrome: Not always ulcerated. South Med J 1992;85:1033-4.

5. Eu KW, Seow-Choen F. Functional problems in adult rectal prolapse and controversies in surgical treatment. Br J Surg 1997;84:904-11.

6. Kochhar R, Malik AK, Nanda V, et al. Clinical spectrum of solitary rectal ulcer. Indian J Gastroenterol 1987;6:31-3.

7. Vora IM, Sharma J, Joshi AS. Solitary rectal ulcer syndrome and ranging from $19 \%$ to $70 \%(15,19)$. Because some patients may have a predominant behavioural disorder of excessive straining with defecation, biofeedback and retraining may be beneficial $(15,20)$. Biofeedback typically includes correction of the pelvic floor defecatory behaviour; regulation of toileting habits; encouragement to stop laxatives, suppositories and enemas; and an attempt to discuss any psychosocial factors that may contribute to their behaviour $(15,20)$. It is often used as an adjunct to surgery and has shown successful results in case series with limited long term follow-up.

In a review by Tjandra et al (1), only 59 of 80 patients had symptoms of SRUS. A limited number (19\%) of this subgroup responded to conservative measures alone; $35 \%$ of patients had no change in symptoms but these results were not significant enough to warrant surgery, and 27 of 59 $(46 \%)$ patients underwent surgery for worsening or intractable symptoms. These surgeries included a total of 31 procedures in 27 patients including rectopexy, Ripstien procedure, resection and diversion. Overall, complete symptomatic relief occurred in 20 of the 31 (65\%) surgical procedures, with a better response rate noted in patients with polypoid lesions than in those with an ulcerated or inflammatory lesion (1). However, when evaluating surgery for SRUS, Sitzler et al (21) noted that antiprolapse operations resulted in a satisfactory long term outcome (minimum follow-up 12 months) in about $55 \%$ to $60 \%$ of patients, with results of anterior resection being especially disappointing.

\section{CONCLUSIONS}

Eroded polypoid hyperplasia is probably a part of the rectal findings in SRUS. This unusual entity may masquerade as rectal neoplasia, proctitis, colitis cystica profunda and juvenile polyposis. Mucorrhea due to altered mucin production and predominance of sialomucin is a unique clinical feature in this condition. When such lesions are seen, rectal prolapse should be considered. Medical management including biofeedback can be attempted but has had limited success. If symptoms persist, surgical treatment should be undertaken.

colitis cystica profunda - a clinico-pathological review. Indian J Pathol Microbiol 1992;35:94-102.

8. Malik AK, Bhaskar KVS, Kochhar R, et al. Solitary ulcer syndrome of the Rectum - a histopathologic characterization of 33 biopsies. Indian J Pathol Microbiol 1990;33:216-20.

9. Mackle EJ, Parks TG. The pathogenesis and pathophysiology of rectal prolapse and solitary rectal ulcer syndrome. Clin Gastroenterol 1986;15:985-1001.

10. Tjandra JJ, Fazio VW, Petras RE, et al. Clinical and pathologic factors associated with delayed diagnosis in solitary rectal ulcer syndrome. Dis Colon Rectum 1993;36:146-53.

11. Khan EM, Pandey R. Histological and mucin secretion patterns in solitary rectal ulcer syndrome. Indian J Gastroenterol 1992;12:47-8.

12. Ehsanulla M, Filipe MI, Gazzard B. Morphological and mucin secretion criteria for differential diagnosis of solitary ulcer syndrome and non-specific proctitis. J Clin Pathol 1982;35:26-30. 
13. Burke AP, Sobin LH. Eroded polypoid hyperplasia of the rectosigmoid. Am J Gastroenterol 1990;85:975-80.

14. Cho NH, Park CI, Ahn AJ. Clinicopathologic comparison of eroded polypoid hyperplasia and solitary rectal ulcer syndrome. J Korean Med Sci 1994;9:319-27.

15. Vaizey CJ, Van Den Bogaerde JB, Emmanuel AV, et al. Solitary rectal ulcer syndrome. Br J Surg 1998;85:1617-23.

16. Levine MS, Piccolello ML, Sollenberger LC, et al. Solitary rectal ulcer syndrome: a radiologic diagnosis? Gastrointest Radiol 1986;11:187-93.

17. Goei R, Baeten C, Janevski B, van-Engelshoven J. The solitary rectal ulcer syndrome: diagnosis with defecography. AJR Am J Roentgenol 1987;149:933-6.

18. Keighley MR, Shouler P. Clinical and manometric features of the solitary rectal ulcer syndrome. Dis Colon Rectum 1984;27:507-12.

19. Van den Brandt Gradel V, Huibregtse K, Tytgat GN. Treatment of solitary rectal ulcer syndrome with high-fiber diet and abstention of straining at defecation. Dig Dis Sci 1984;29:1005-8.

20. Binnie NR, Papachrysostomou M, Clare N, et al. Solitary rectal ulcer: the place of biofeedback and surgery in the treatment of the syndrome. World J Surg 1992;16:836-40.

21. Sitzler PJ, Kamm MA, Nicholls RJ, McKee RF. Long-term clinical outcome of surgery for solitary rectal ulcer syndrome. Br J Surg $1998 ; 85: 1246-50$

22. Levine DS, Surawicz CM, Ajer TN, et al. Diffuse excess mucosal collagen in rectal biopsies facilitates differential diagnosis of solitary rectal ulcer syndrome from other inflammatory bowel diseases. Dig Dis Sci 1988;33:1345-52.
23. Tsuchida K, Okayama N, Miyata M, et al. Solitary rectal ulcer syndrome accompanied by submucosal invasive carcinoma. Am J Gastroenterol 1998;93:2235-8.

24. Allen MS. Hamartomatous inverted polyps of the rectum. Cancer 1966;19:257-65

25. Wilcox CM, Schwartz DA. Idiopathic anorectal ulceration in patients with human immunodeficiency virus infection. Am J Gastroenterol 1994;89:599-604.

26. Tedesco FJ, Volpicelli NA, Moore FS. Estrogen- and progesteroneassociated colitis: A disorder with clinical and endoscopic features mimicking Crohn's colitis. Gastrointest Endosc 1982;28:247-9.

27. Naumann MG, Hintze R, Karaus M. Solitary rectal ulcer induced by excessive use of analgesic suppositories containing paracetamol, caffeine, and codeine. Am J Gastroenterol 1998;93:2573-6.

28. Shpilberg O, Ehrenfeld M, Abramowich D, et al. Ergotamine-induced solitary rectal ulcer. Postgrad Med J 1990;66:483-5.

29. Hixson LJ. Colorectal ulcers associated with sodium phosphate catharsis. Gastrointest Endosc 1995;42:101-2.

30. Knigge KL, Katon RM. Massive hematochezia from a visible vessel within a stercoral ulcer: effective endoscopic therapy. Gastrointest Endosc 1997;46:369-70.

31. Gelblum DY, Potters L. Rectal complications associated with transperineal interstitial brachytherapy for prostate cancer. Int J Radiat Oncol Biol Phys 2000;48:119-24.

32. Bolanos G, Camps JI, Figueroa JI, et al. Rectosigmoid lipoma an unusual colonic lipoma. Case report and review of the literature. Bol Assoc Med P R 1994;86:53-5. 


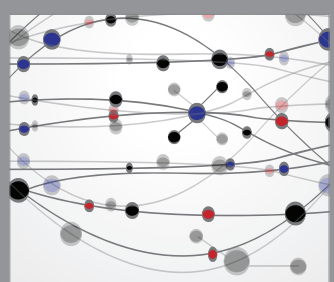

The Scientific World Journal
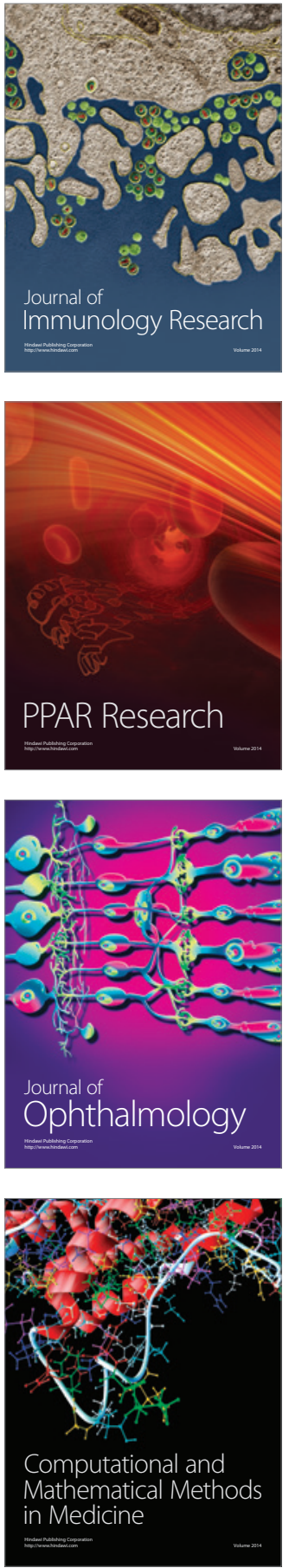

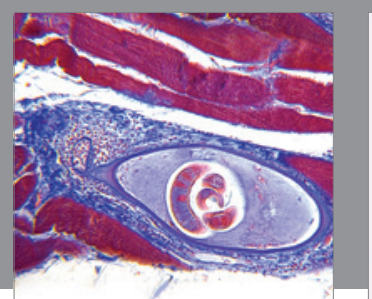

Gastroenterology Research and Practice

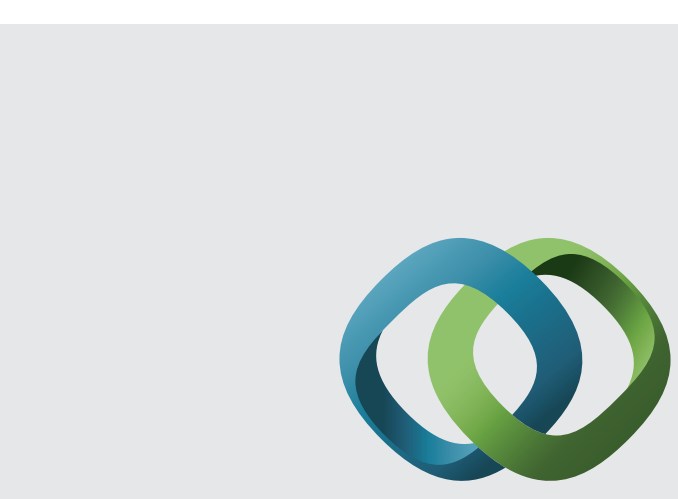

\section{Hindawi}

Submit your manuscripts at

http://www.hindawi.com
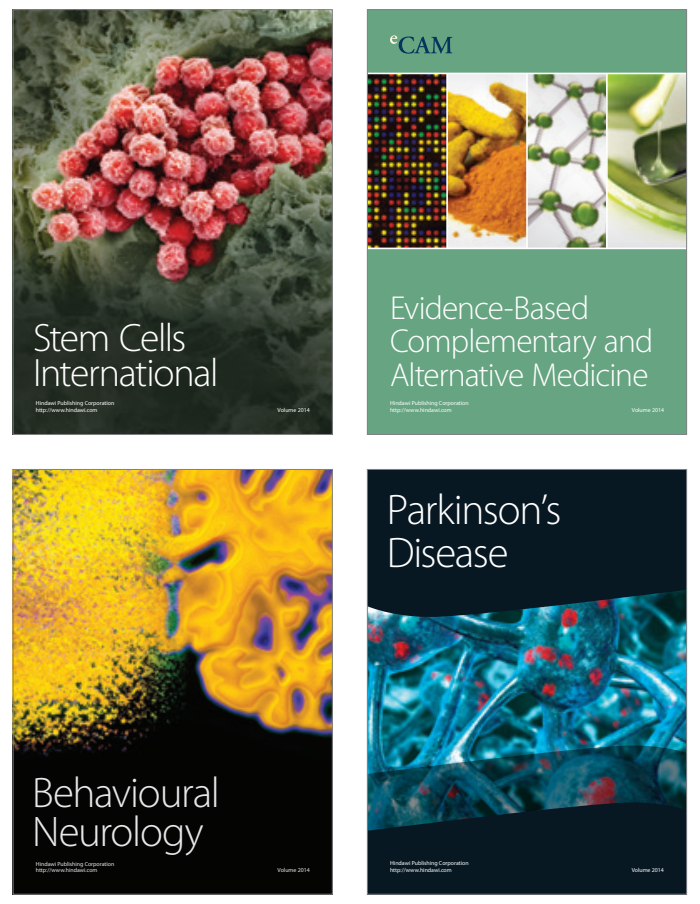
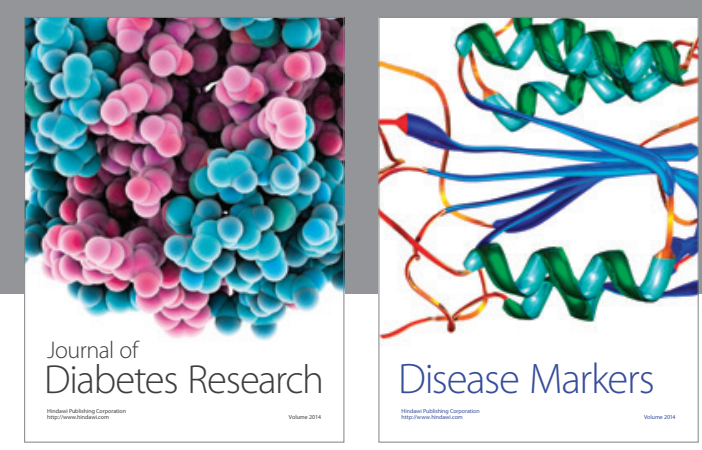

Disease Markers
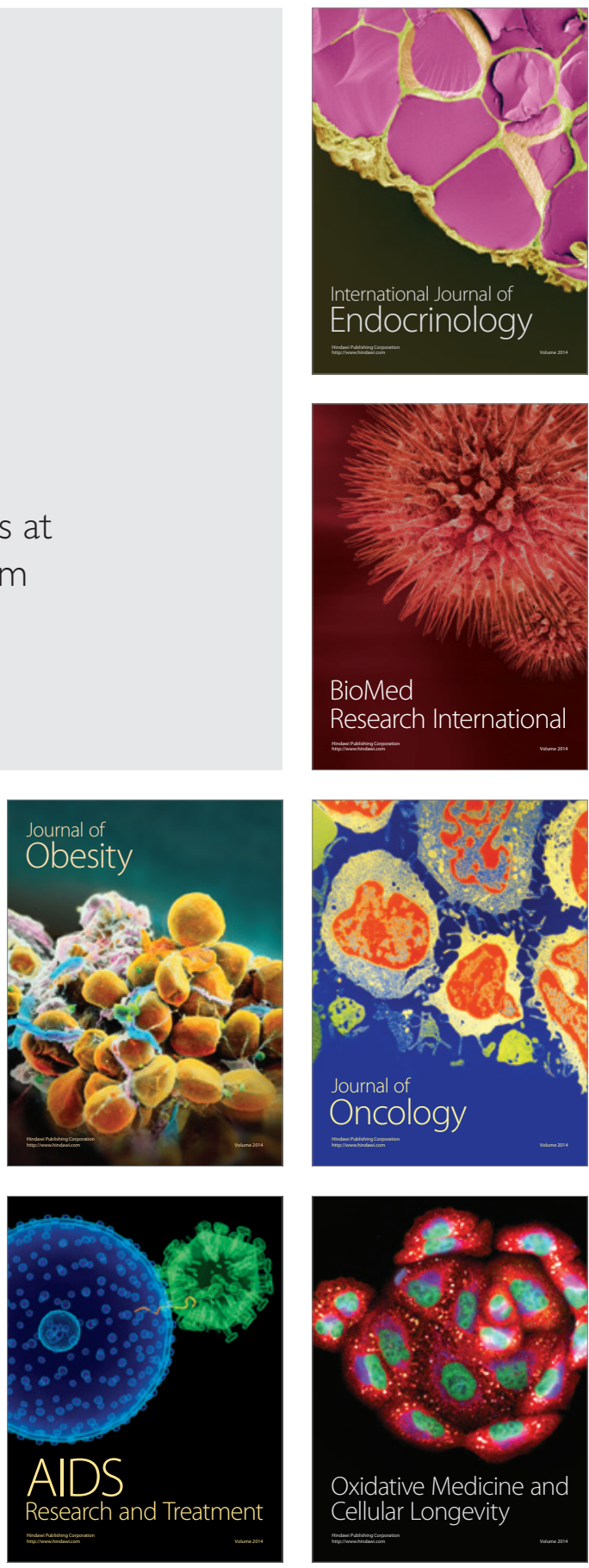